\title{
A case of pancreatic schwannoma with a focus on contrast-enhanced endoscopic ultrasonography
}

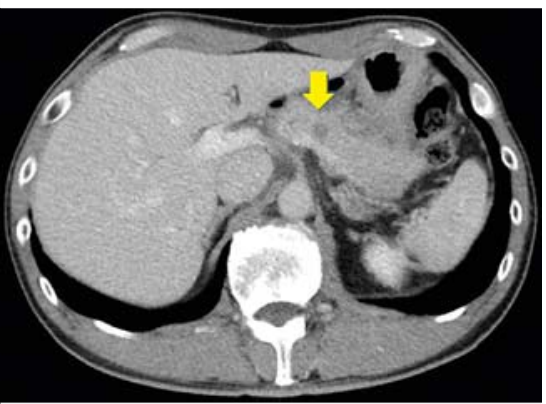

- Fig. 1 Contrast-enhanced computed tomography revealed a $10-\mathrm{mm}$ hypovascular tumor (arrow) in the pancreatic body.

A schwannoma is a benign peripheral nerve sheath tumor originating from Schwann cells [1]. Although schwannomas appear as well-demarcated hypoechoic masses on endoscopic ultrasonography (EUS) [2], there are few reports on pancreatic schwannoma diagnosed by EUS. A pancreatic schwannoma is difficult to diagnose preoperatively because of the lack of established imaging characteristics. We present a case of pancreatic schwannoma that was diagnosed by contrast-enhanced EUS and endoscopic ultrasound-guided fine-needle aspiration (EUS-FNA).

A 54-year-old man was admitted to our hospital with a $12-\mathrm{mm}$ tumor in the pancreatic body. The tumor was revealed on ultrasonography during a medical checkup without any symptoms. Contrast-enhanced computed tomography revealed a $10-\mathrm{mm}$ hypovascular tumor in the pancreatic body ( Fig. 1 ). Magnetic resonance imaging of the tumor revealed hypointensity on T1-weighted images, hyperintensity on T2-weighted images, and hyperintensity on diffusion-weighted images ( Fig.2). No abnormalities were observed on magnetic resonance cholangiopancreatography. EUS showed a 12-mm, clear-boundary, solid, round, and hypoechoic tumor in the pancreatic body. Contrast-enhanced EUS showed a
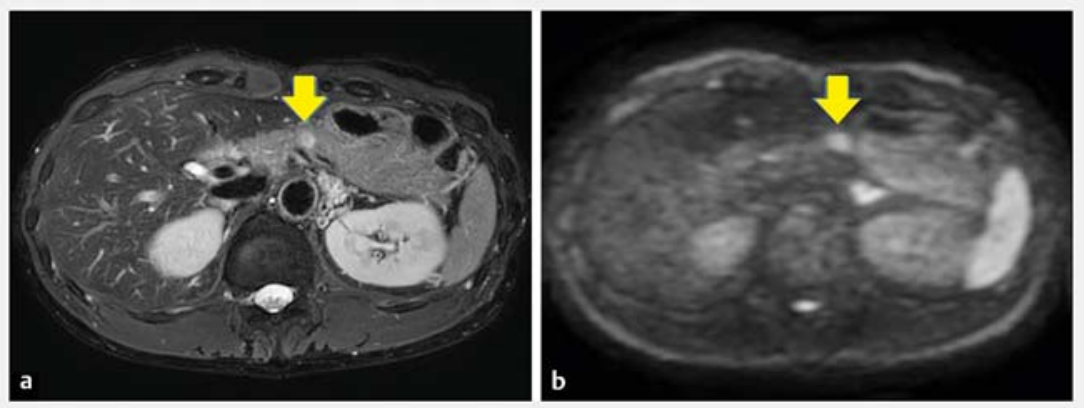

- Fig. 2 Magnetic resonance imaging and magnetic resonance cholangiopancreatography. a A T2-weighted image shows a hyperintensity (arrow). b A diffusion-weighted image shows a hyperintensity (arrow).
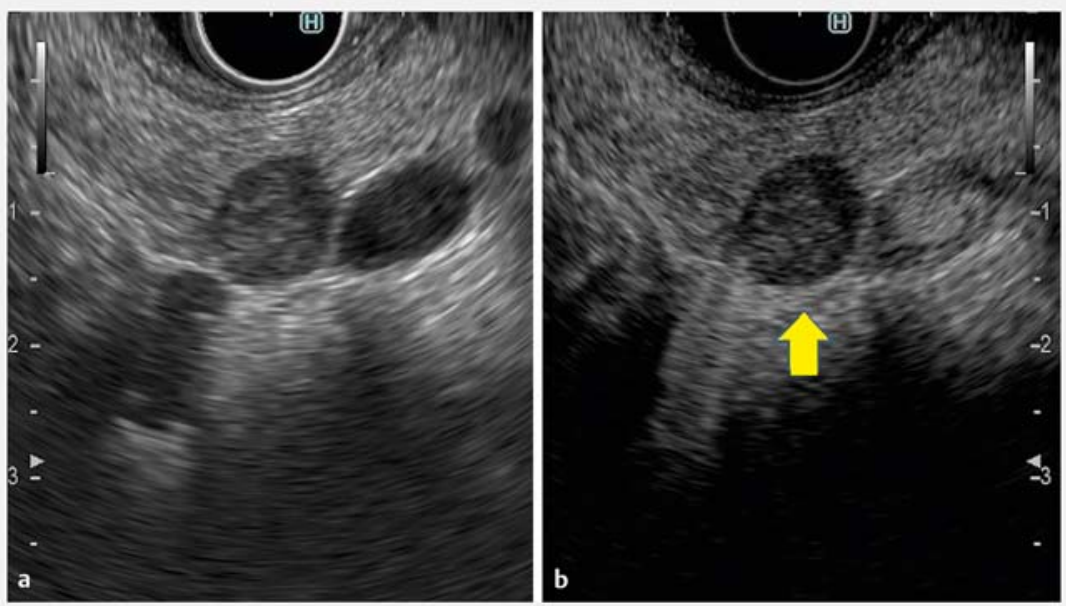

- Fig. 3 Contrast-enhanced endoscopic ultrasonography showed a hypovascular tumor compared with the surrounding pancreatic parenchyma.

hypovascular tumor compared with the surrounding pancreatic parenchyma ( Fig.3), and contrast-enhanced EUS findings were observed continuously over 2 minutes ( $\downarrow$ Video 1 ). We performed EUS-FNA with a 22-gauge needle (Sono Tip Pro Control; Medi-Globe $\mathrm{GmbH}$, Rosenheim, Germany) to make a pathological diagnosis. Histopathological examination revealed a proliferation of spindle cells. These tumor cells were positive for $\mathrm{S}-100$ protein and negative for c-kit and desmin in immunohistochemical staining ( $\mathbf{F i g} \mathbf{4}$ ). Based on these findings, the lesion was diagnosed as a schwannoma. The patient was carefully monitored without surgical resection.

Contrast-enhanced EUS images of this tumor had a slightly delayed enhancement; therefore, a solid pseudopapillary neoplasm and pancreatic neuroendocrine neoplasm were considered as differential diagnoses [3]. In conclusion, small 


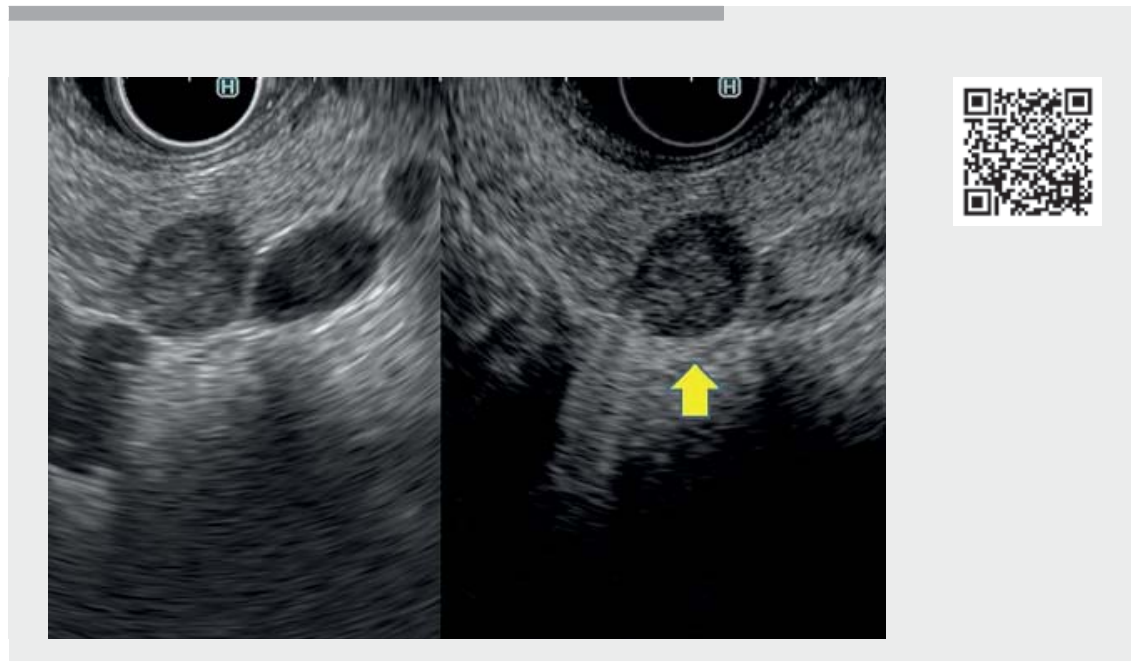

Video 1 Hypovascular tumor compared with surrounding pancreatic parenchyma on contrast-enhanced endoscopic ultrasonography, observed continuously over 2 minutes. Cystic components were undetected. Endoscopic ultrasound-guided fine-needle aspiration was performed using a 22-gauge needle.

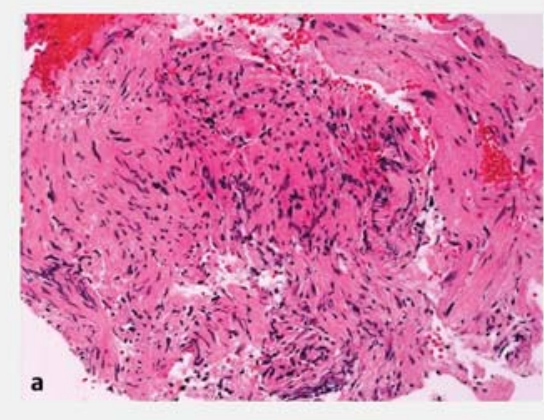

- Fig. 4 Histopathology of endoscopic ultrasound-guided fine-needle aspiration. a Fascicles of spindle cells were observed (hematoxylin and eosin stain; high power field). b Immunohistochemical staining of these cells was positive for S-100 protein (high power field).

and solid schwannomas may resemble solid pseudopapillary neoplasms and pancreatic neuroendocrine neoplasms. Therefore, contrast-enhanced EUS and EUS-FNA may be useful in avoiding surgical resection.

Endoscopy_UCTN_Code_CCL_1AF_2AZ_3AB

Competing interests

The authors declare that they have no conflict of interest.

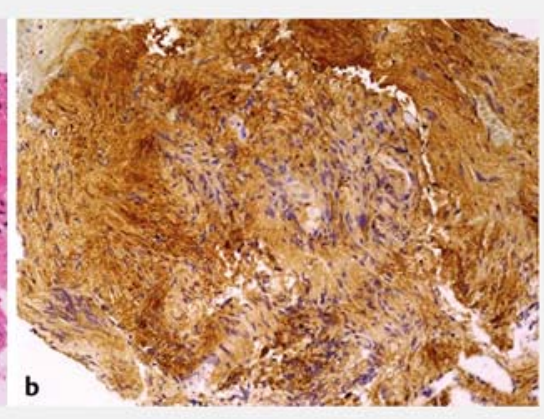

Corresponding author

\section{Tsuyoshi Sanuki, MD}

Department of Gastroenterology, KitaHarima Medical Center, 926-250 Ichiba-cho, Ono, Hyogo, 675-1392, Japan

Fax: +81-794-62-9931

tssanuki@gmail.com

References

[1] Verocay J. Zur Kenntnis der Neurofibrome. Beitr Pathol Anat 1910; 48: 1-69

[2] Ma Y, Shen B, Jia Y et al. Pancreatic schwannoma: a case report and an updated 40 -year review of the literature yielding 68 cases. BMC Cancer 2017; 17: 853

[3] Ishikawa T, Itoh A, Kawashima H et al. A case of solid-pseudopapillary neoplasm, focusing on contrast-enhanced endoscopic ultrasonography. J Med Ultrason 2011; 38: 209216

\section{Bibliography}

Endoscopy 2022; 54: E166-E167

DOI 10.1055/a-1422-1763

ISSN 0013-726X

published online 28.4.2021

(c) 2021. Thieme. All rights reserved.

Georg Thieme Verlag KG, Rüdigerstraße 14,

70469 Stuttgart, Germany

\section{ENDOSCOPY E-VIDEOS}

https://eref.thieme.de/e-videos

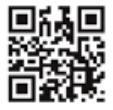

Endoscopy E-Videos is an open access online section, reporting on interesting cases and new techniques in gastroenterological endoscopy. All papers include a high quality video and all contributions are freely accessible online. Processing charges apply (currently EUR 375), discounts and wavers acc. to HINARI are available.

1 Department of Gastroenterology, KitaHarima Medical Center, Ichiba, Ono, Hyogo, Japan

2 Department of Pathology, Kita-Harima Medical Center, Ichiba, Ono, Hyogo, Japan

This section has its own submission website at

https://mc.manuscriptcentral.com/e-videos 